\title{
Solar and wind energy resources of the Eger Region
}

\author{
János MIKA ${ }^{1}$, Edina KitTi CSABAI ${ }^{1}$, ILdikó DOBI ${ }^{2}$, Zsófia MOLNÁR², \\ ZOLTÁN NAGY², ANDRÁs RÁZSI ${ }^{1,3}$, ZsUZSANNA TÓTH-TARJÁNYI ${ }^{2}$ and \\ ILONA PAJTÓK-TARI ${ }^{1}$
}

\begin{abstract}
The spatial interpolation and mapping of renewable energy resources is an important task of potential estimation of atmospheric renewable energy sources. First the global radiation on horizontal surfaces and near-surface wind speed at $10 \mathrm{~m}$ height above the surface (not at $60-120 \mathrm{~m}$, which is the height of contemporary wind turbines) is measured. Based on standard meteorological observations, the experts of the Hungarian Meteorological Service elaborated a series of digital maps with $0.1^{\circ} \times 0.1^{\circ}$ resolution. The grid-point values are based on homogenised data using MASH theory and software. The study tackles solar and wind energy from four aspects. Firstly, a trial for validation of the gridded data is provided by a comparison between a single station, Eger and the very closely located grid-point values. Secondly, the annual cycles of the areal-mean global radiation and wind speed are presented, based on the gridded data of a selected area of $50 \times 50 \mathrm{~km}$. Both the averages and the standard deviations of the diurnal mean values are presented for the 1981-2010 reference period. Presenting the maps of the distribution within the area is the third issue with average and standard deviation values. Finally, the point-wise trends are drawn for both energy sources in the single grid-point used in the aspect one in 1981-2010 and also in the nearby located stations for comparison. The trend of solar energy is positive, whereas the trend for wind energy (speed cube) is negative in the given 30 year period. Since, mainly warming characterised those three decades in the Northern Hemisphere, the trends might also be interpreted as responses to the large-scale forcing, though the observed behaviour does not necessarily mean causal relationship with the global tendencies.
\end{abstract}

Keywords: global radiation, wind energy, Eger Region, annual cycle, climate change

\footnotetext{
${ }^{1}$ Eszterházy College, H-3300 Eger, Eszterházy tér 1. E-mails: mikaj@ektf.hu, ecsabai@gmail. com, razsia@ektf.hu, pajtokil@ektf.hu

${ }^{2}$ Hungarian Meteorological Service, H-1024 Budapest, Kitaibel Pál u. 1. E-mails: dobi@met. hu, nagy.z@met.hu, tarjanyi.zs@met.hu

${ }^{3}$ Hungarian Meteorological Service, Regional Centre, H-3530 Miskolc, Petőfi S. u. 18. E-mails: razsi.a@met.hu, molnar.zs@met.hu
} 


\section{Introduction}

The development of society and economy is often determined by climate, topography and water availability. This relationship is in the focus of our present research on renewable energy sources and energy efficiency in the Eger Energy Region, NE Hungary. Natural conditions for the utilisation of the resources and the associated societal conditions will be discussed in the paper. The Eger Energy Region consists of 23 settlements including the county seat, Eger. The area of the region is $718 \mathrm{~km}^{2}$; its population was 92,483 inhabitants in 2009 .

The present study deals with solar and wind energy. Results of spatial and temporal analyses of global radiation and wind speed data will be presented below. Gridded data values will be compared with those of one single station located very close to one of the grid-points. The annual cycle of the area-mean values and the standard deviations of the diurnal means as well as distributions will be presented. Finally, the point-wise linear trends of annual and seasonal solar radiation and wind cube values will be given for the grid-points.

\section{Data and methods}

In the meteorological practice, solar energy is observed on a horizontal surface. Wind energy is related to 10-metre height above the ground. None of them is considered as maximum available energy since the optimally directed and tilted solar cells as well as the higher-elevated wind turbines will provide more energy. Nevertheless, the smooth spatial distribution of both energy sources provide a first insight into the availability of the energy, since direction and tilt modify the energy independently of the spatial coordinates, except in the case of extreme topographical conditions. The logarithmic dependence of wind speed from the height does not explicitly vary with horizontal coordinates, either.

The presented results are mainly based on grid-point data in a ca. $50 \times 50 \mathrm{~km}$ area containing the Eger Energy Region (Figure 1). More exactly, the gridded data are characterised by their geographic limits of are $47.6^{\circ}$ and $48.1^{\circ}$ Northern latitudes and $20.0^{\circ}$ and $20.7^{\circ}$ Eastern longitudes. The gridded data obtained by the experts of the Hungarian Meteorological Service are also available on the Internet (www.carpatclim-eu.org). The interpolation was performed for the whole country also involving some near-border stations of the neighbouring countries. Hence it is difficult to assess how many stations were involved in the interpolation. From the meta-data, one can establish that allowing $0.6^{\circ}-0.6^{\circ}$ wider areas than the rectangle, the area contains 7 stations for wind speed but only two stations for sunshine duration. The data series is available for 1961-2010, but we use the data of the 1981-2010 period which coincides with a more or less even warming period in the Northern hemisphere which is also confirmed by the recent IPCC AR5 Report (IPCC, 2013). 


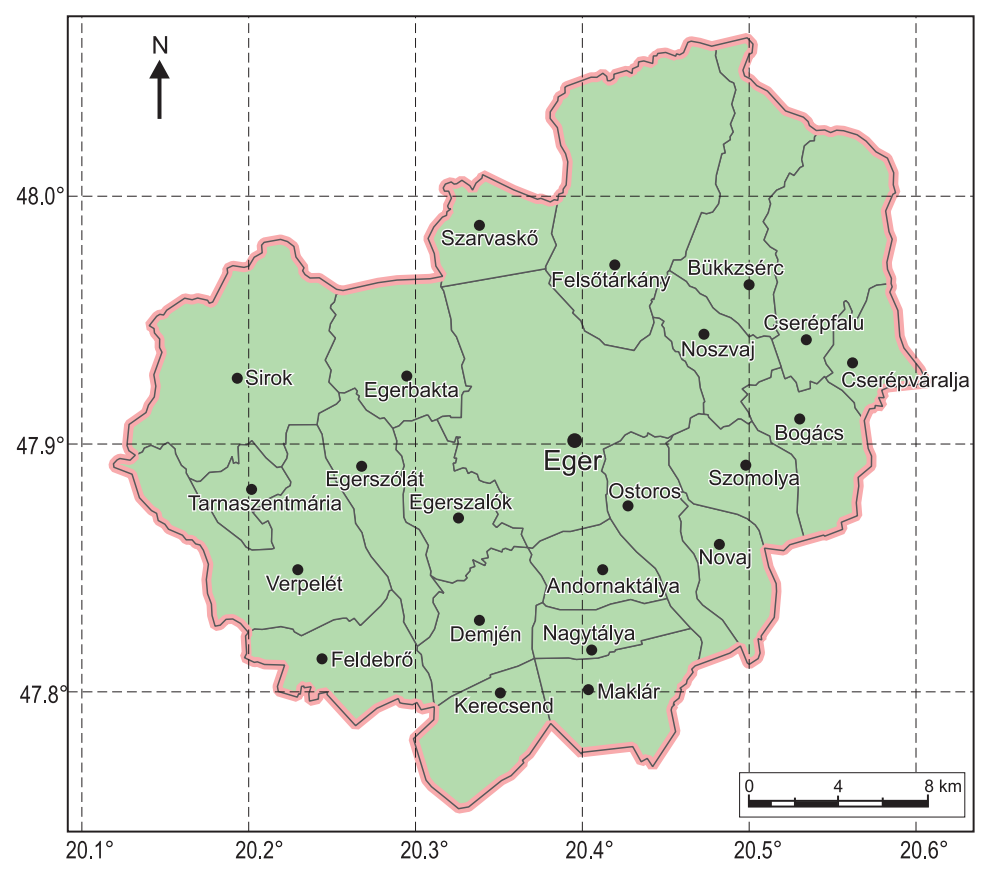

Fig. 1. The Eger Energy Region in the $0.1^{\circ} \times 0.1^{\circ}$ geographical network with the single station called Eger. The other lines represent the administrative areas of the 23 settlements of the region

The area of computations is characterised by variable topography, though the majority of the highest hills of the investigated rectangle are not included in the region. The average height of the rectangle is $205 \mathrm{~m}$, the standard deviation of the elevation of the 48 grid-points is $150 \mathrm{~m}$. The highest located grid-point is at $866 \mathrm{~m}$ a.s.l., whereas the lowest point is at $86 \mathrm{~m}$ a.s.l.. There are 12 grid-points below $100 \mathrm{~m}$ a.s.l. and again 12 grid-points above $300 \mathrm{~m}$ a.s.l.. For these features are considered by the interpolation methodology is applied.

The input data of the stations underwent on a homogenisation process ("MASH" by SzentimRey, T. 1999) to avoid non-realistic fluctuations and to obtain a statistically optimal interpolation ("MISH" by SzENTIMreY, T. and BIHARI, Z. 2006). The latter does not only use the spatial correlation of the elements but also the temporal correlation which is not known in any other spatial interpolation methodology. Both statistical processes are described by the authors at http://www.carpatclim-eu.org/docs/mashmish/mashmish.pdf.

In the given database wind data are derived from direct measurements, but solar radiation data are estimated from sunshine duration applying the method of Angström, A. (1924) modified by Prescott, J.A. (1940). 
For comparison, the point-wise observed data measured by the standard meteorological station of Eger $\left(47.90^{\circ} \mathrm{N}, 20.39^{\circ} \mathrm{E}, 225 \mathrm{~m}\right.$ a.s.l.) are also used for much shorter periods, namely the data of 2001-2010 for global radiation and those of 1996-2010 for wind speed. The point-wise values are compared with the grid-point data at the point of $47.90^{\circ} \mathrm{N}$ latitude and $20.40^{\circ} \mathrm{E}$ longitude. One must note that the station Eger was not involved in the grid-point value derivation due to the sparse data availability in 1961-2010.

The statistical calculations applied below are fairly simple: averaging is based on the diurnal values. Standard deviations are also computed for the diurnal values to represent diurnal variability of the available energy. The trends are determined by the method of least squares. The significance of the trends is not estimated, the correlation coefficients are added for orientation.

The validations of the gridded data both for global radiation and wind speed cube for Eger are presented in the next part of the paper. The validation is crucial from the point of view of feasibility to apply the gridded data in the evaluation of energy potential in the region.

The annual cycles of the gridded global radiation and wind speed data based on the area mean values will also be presented. Not only the annual cycle of the means but also the standard deviations are in the scope of the evaluations to describe the stability of the available potential.

The estimated spatial differences for the climatic means and standard deviations of January and July months will be detailed too. Geographical distribution around the mean values is also mapped exhibiting interesting spatial patterns despite the small size of the investigated rectangle.

Finally, we return to the point-wise values of Eger to explore the longterm tendencies in the time variations of global radiation and wind cube at 10-m height.

\section{Validation of the grid-point data}

The first important question concerning the grid-point data is whether they reflect the real values correctly, especially under the circumstances of complex topography. We could make this comparison only between the meteorological station of Eger and the nearby grid-point. The horizontal distance between them is less than $1 \mathrm{~km}$. Note that the station was always involved in the interpolation.

\section{Global radiation}

Table 1 represents a fair agreement between the global radiation of grid-point $\left(R_{c c}\right)$ and the observation by the station $\left(R_{o b s}\right)$. The difference between the 
Table 1. Basic statistics for global radiation in Eger and in the nearest grid-point

\begin{tabular}{l|c|c|c}
\hline \multicolumn{1}{c|}{$\mathrm{MJ} / \mathrm{m}^{2} /$ day } & $\mathrm{R}_{\mathrm{cc}}$ & $\mathrm{R}_{\mathrm{cc}}$ & $\mathrm{R}_{\mathrm{obs}}$ \\
\hline \multicolumn{1}{c|}{ Period } & $1981-2010$ & \multicolumn{2}{c}{$2001-2010$} \\
\hline Mean & 12.00 & 12.27 & 12.06 \\
Median & 10.67 & 11.00 & 10.61 \\
Standard deviation & 7.59 & 8.36 & 8.44 \\
Minimum & 2.09 & 0.39 & 0.00 \\
\hline Maximum & 29.46 & \multicolumn{2}{|c}{31.25} \\
No of days & 10,957 & \multicolumn{2}{|c}{3,652} \\
\hline
\end{tabular}

means of the 30-year period and the means of the 10-year period is rather significant though in case of comparing the shorter station data series with the identical gridded data, the difference is increasing. That statement also refers to the medians. The standard deviation values taken from the identical ten-year periods, however, are closer to each other. The maxima and the minima are fairly close to each other, as well. So, the grid-point values can be considered as a fair approximation for global radiation with no considerable biases.

\section{Wind speed}

Unfortunately the grid-point values of wind speed cubes $\left(F_{c c}\right)$, i.e. the first approaches of the available wind energy (Table 2) do not perform so well. The 30-year climate estimate is 50\% larger than values observed at the station $\left(\mathrm{F}_{\mathrm{obs}}\right)$ during a 15-year period. About half of the difference disappears if we compare the identical time periods. The remaining difference is still $25 \%$, i.e. the gridded values overestimate the wind cubes by that value. The medians are also a bit overestimated.

Table 2. Basic statistics for wind-cube in Eger and in the nearest grid-point

\begin{tabular}{l|c|r|r}
\hline \multicolumn{1}{c|}{$(\mathrm{m} / \mathrm{s})^{3}$} & $\mathrm{~F}_{\mathrm{cc}}$ & $\mathrm{F}_{\mathrm{cc}}$ & $\mathrm{F}_{\mathrm{obs}}$ \\
\hline \multicolumn{1}{c|}{ Period } & $1981-2010$ & \multicolumn{2}{c}{$1996-2010$} \\
\hline Mean & 30.07 & 25.07 & 19.94 \\
Median & 10.65 & 10.22 & 9.26 \\
Standard deviation & 69.29 & 52.18 & 34.38 \\
Minimum & 0.02 & 0.06 & 0.00 \\
Maximum & $1,702.21$ & $1,401.17$ & 614.13 \\
\hline No of days & 10,957 & \multicolumn{2}{|c}{5,479} \\
\hline
\end{tabular}


The standard deviation of daily values differs even more significantly. The difference between the 30 years grid-point values and the 15 years station values is above $100 \%$, roughly the half of which remains when comparing the identical periods but different data. This strong overestimation peaks in case of maxima with almost threefold difference between the 30-year gridded and 15 years local data. Due to the difference, the statistics of wind will be mapped only for its first power (instead of its cube).

We would like to emphasise again that the Eger station was not involved in the grid-point value derivation, since the observations were performed at different sites during the basic 1961-2010 interpolation period. The above validation is a good example for any point of the Eger region, because the grid-point data are completely independent from the station-data.

\section{Areal-mean daily statistics}

\section{Averages of global radiation and wind speed}

Figure 2 illustrates the annual cycle of global radiation and wind speed by the areal mean values based on the gridded data, also indicating the highest and the smallest values of the 30 years average values of monthly total radiation and monthly mean wind speed. The July maximum of global radiation is slightly over the June value explained by the annual minimum of cloudiness in July.

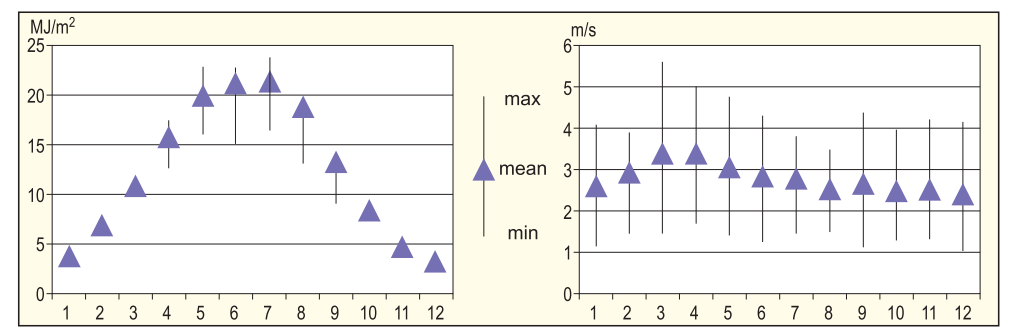

Fig. 2. Annual cycle of global radiation $\left(\mathrm{MJ} / \mathrm{m}^{2}\right.$ ) (left) and the mean wind speed $(\mathrm{m} / \mathrm{s})(\mathrm{right})$ by the areal mean values with the lowest and highest point-wise averages in 1981-2010

\section{Standard deviations of the diurnal values}

The climatic mean values provide first insights into the available energy resources. The knowledge of diurnal variability around these values is also important. Figure 3 presents the standard deviations for the daily sums of global radiation and the daily mean wind speed which, certainly, reflect the strong annual cycle of global radiation, but they behave differently from the annual cycle of wind speed (Figure 2). 


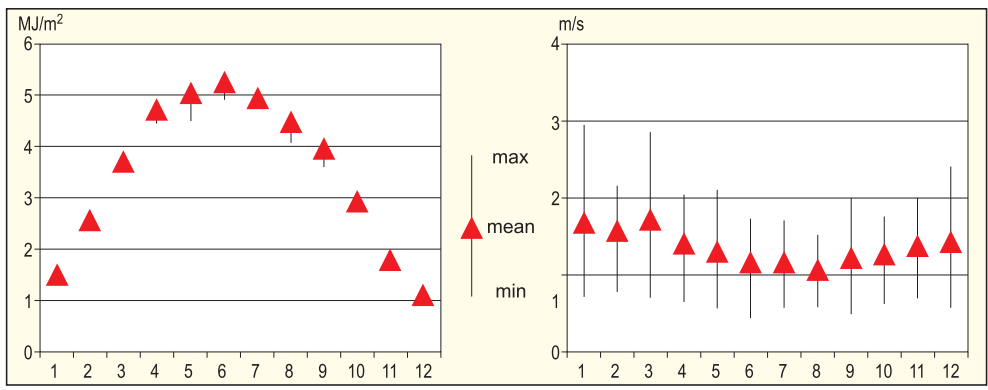

Fig. 3. Annual cycle of standard deviation for diurnal global radiation $\left(\mathrm{M} \mathrm{J} / \mathrm{m}^{2}\right)$ and that of wind speed by the areal average values with maxima and minima of the region (1981-2010)

\section{Mapping diurnal means and standard deviations}

\section{Global radiation}

Figure 4 illustrates the spatial distribution of global radiation in January and in July. The data represent the diurnal mean values. The maps were created by the ArcGIS software. The annual cycle of global radiation is mainly determined by the astronomical differences at the given latitude, i.e. the early summer maximum of the zenith angle, the length of daylight and by the annual cycle of cloudiness which is the lowest in July.

The standard deviation maps of the diurnal data can be seen in Figure 5. Here, again, the fair estimation of standard deviation by the single grid-point value near Eger in the above validation allows for considering the above maps confirming the estimates of the real standard deviations. Only the peak value of standard deviation in the $47.9^{\circ} \mathrm{N} \mathrm{20.0^{ \circ }}$ E grid-point is influenced by the mountainous station of Kékestető located almost there, nearly 1,000 m a.s.l.. Here, cloudiness may cause strong time variations in radiation. That effect is present only in July, but not in January when there are clouds at any elevation.

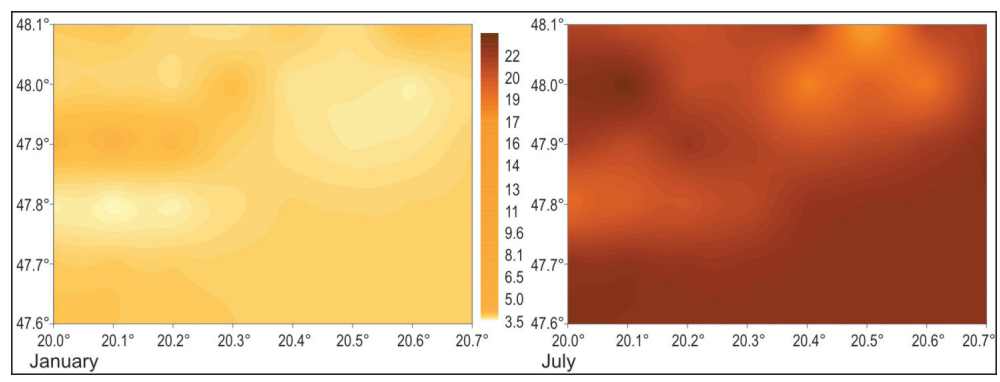

Fig. 4. Average global radiation fields diurnal global radiation at a horizontal plain by the gridded data. Units: $\mathrm{MJ} / \mathrm{m}^{2}$ 


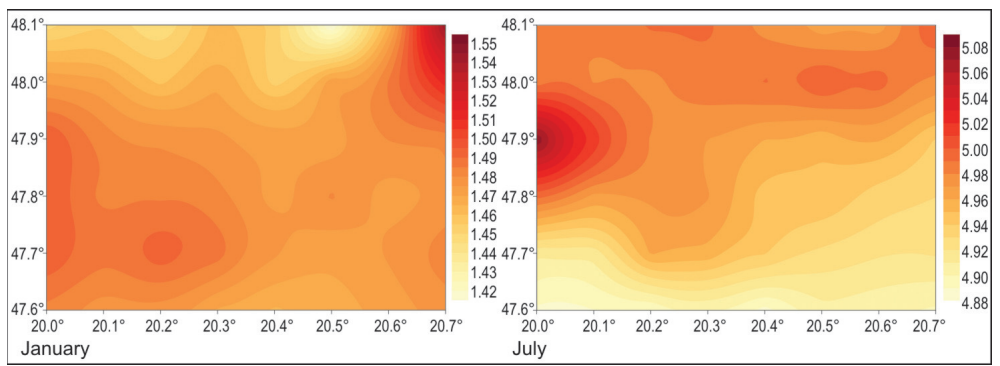

Fig. 5. Standard deviation of diurnal global radiation at a horizontal plain according to the gridded data. Units: $\mathrm{MJ} / \mathrm{m}^{2}$

\section{Wind speed}

Figure 6 presents similar values of wind speed at the 10 meters observation level. The maps indicate even larger relative differences within the area possibly as a consequence of over-interpretation of the topography. The maxima around a few single grid-points are not convincing, either.

The standard deviation values of the diurnal mean values of wind speed can be seen in Figure 7. Their structure also contains some surprising local extremities which are hardly real consequences of the real topography. Hence, even if the maps represent the linear wind speed estimates, the spatial patterns of both the averages and the standard deviation are rather uncertain.
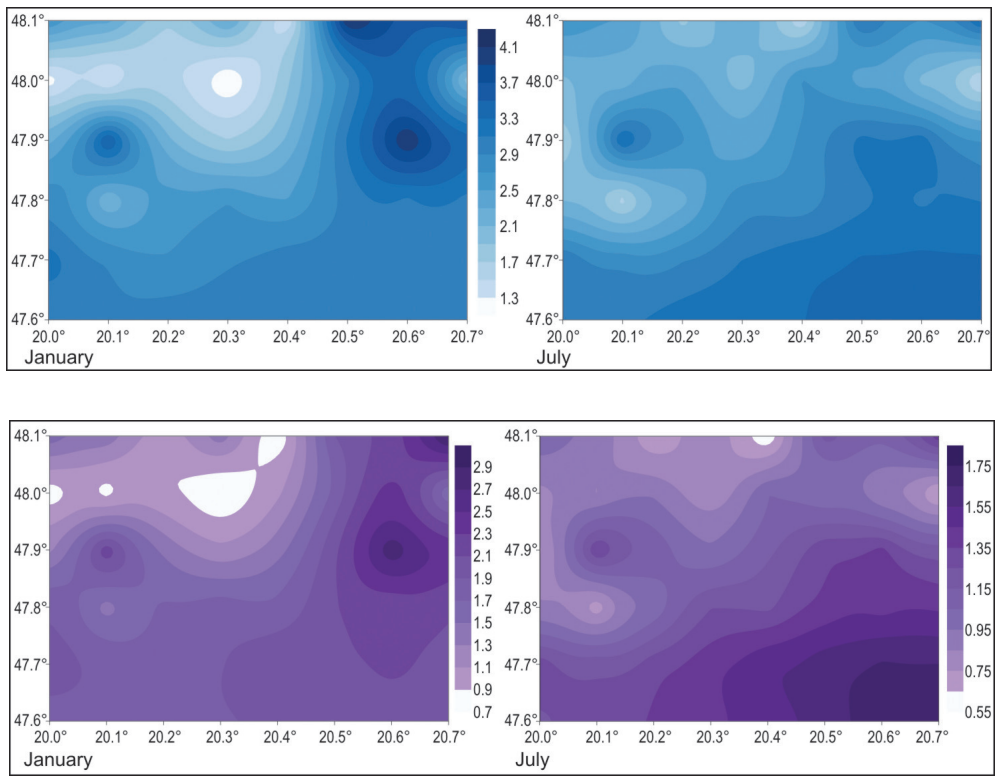

Fig. 6. Average fields of diurnal mean wind speed according to the gridded data. Units: $\mathrm{m} / \mathrm{s}$

Fig. 7. Standard deviation of diurnal mean wind speed at $10 \mathrm{~m}$ above the ground level according to the gridded data 


\section{Observations}

\section{Global radiation}

The long-term trends are presented in a single grid-point located at the shortest distance (ca. $1 \mathrm{~km}$ ) from Eger. The CC series are based on the derived values from sunshine duration (see above). It is fairly convincing that in the last 10 years with frequent observations, the inter-annual fluctuation occurred parallel in the two series (Figure 8).

The annual totals of global radiation exhibit unequivocal moderate trend of $5.31 \mathrm{MJ} / \mathrm{m}^{2}$ year. Comparing it with the average value of the 30-year period, it can be establish that it is the only $1 \%$ per decade. It means that the future development of solar energy industry will hardly depend on the direct effect of climate change.

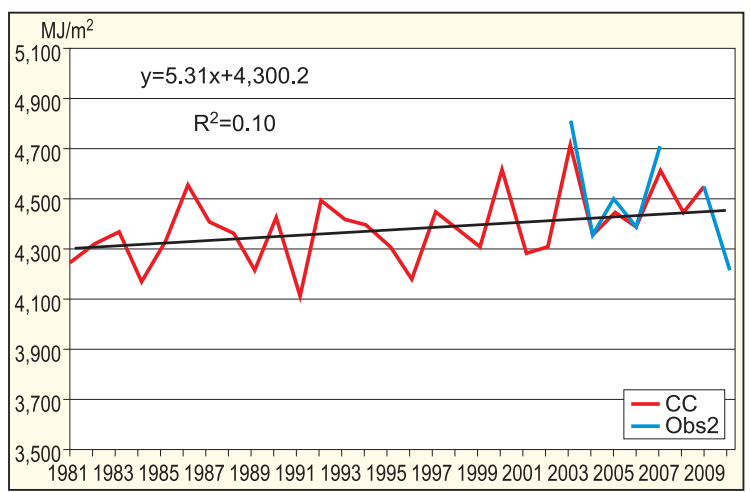

Fig. 8. Trends of annual global radiation $\left(\mathrm{MJ} / \mathrm{m}^{2}\right)$ in the near-Eger grid-point (CC: 1981-2010) and the local observation in Eger (Obs2)

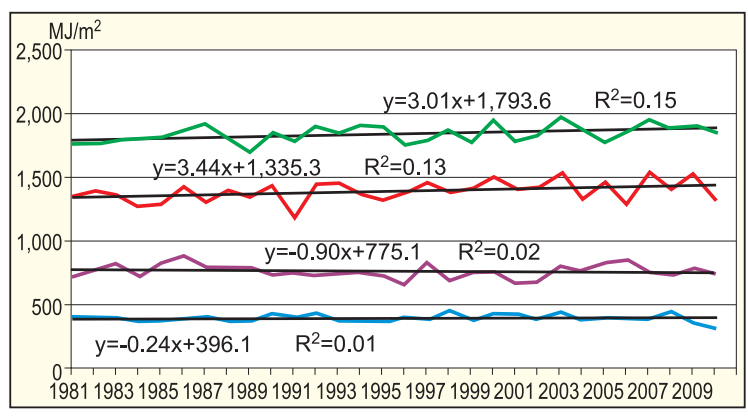

Fig. 9. Seasonal trend lines in the CC series of global radiation with the linear trend and the explained variance (square of correlation coefficient) by the given trends
According to Figure 9 the two seasons with the highest absolute values, i.e. summer and spring exhibit increasing trends, whereas the two other seasons are characterised by decreasing trends. Both the absolute difference and the differences of steepness of the trends support the positive trend of annual global radiation presented in Figure 8. Since the observed 1981-2010 period coincided with a global warming period. The trends can also be interpreted as a result of a monotonically warming period of 30 years.

\section{Wind energy}

The same analysis is performed for wind cube data and their annual means shown in Figure 10. The diagram indicates a considerably decreasing trend in 1981- 


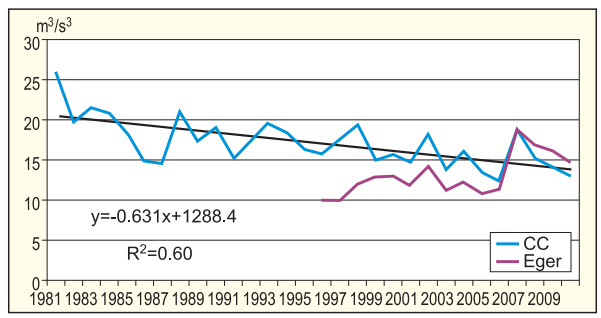

Fig. 10. Trends of the annual mean value of daily mean wind-cube $\left(\mathrm{m}^{3} / \mathrm{s}^{3}\right)$ in the gridpoint nearest to Eger and in the point-wise measurement in Eger
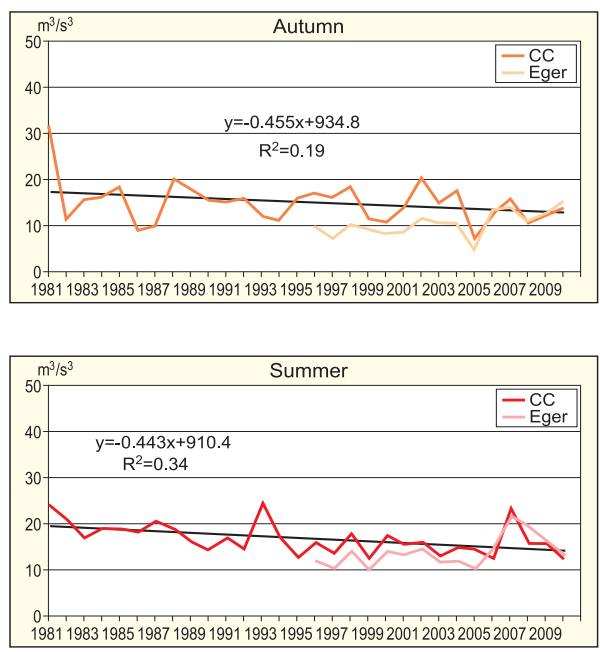

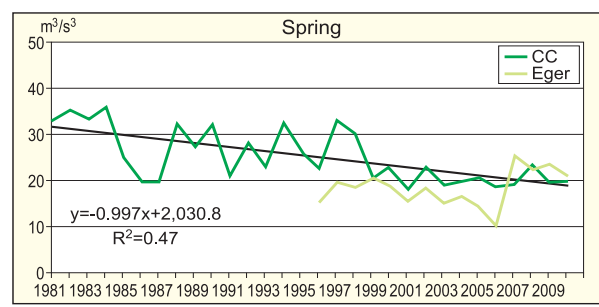

2010. As stated previously, the differences between the gridded and the ever, the strong biases may have been constant during the 30-year period.

The wind speed trends of seasonal means are presented in Figure 11. They equally demonstrate the decreasing tendency which makes the reality of the trend in the annual mean even more convincing.

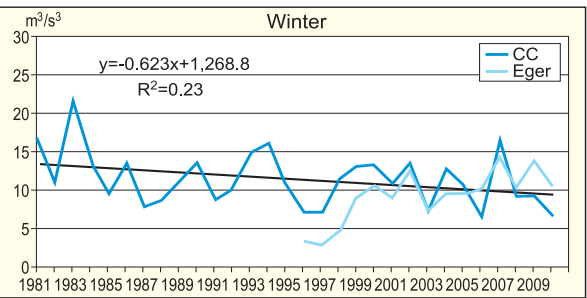
point-wise data are rather big. How-

Fig. 11. Trends of the seasonal mean values of daily mean wind-cube $\left(\mathrm{m}^{3} / \mathrm{s}^{3}\right)$ in the gridpoint nearest to Eger and in the point-wise measurement in Eger

\section{Discussion}

The gridded global radiation data may be considered as fairly good approaches but this is not the case for wind data. In both cases, data compared with the data of Eger station were not involved in the interpolation. Hence, both experiences can be considered to be based on the comparison of independent data.

The presented mapping is based on the probably best available statistical interpolation using input data from the whole country and for some stations near the border. In principle, it promises a better estimation of real 
values than any other interpolation using a smaller dataset. MISH does not only use spatial but also temporal correlations, which may also improve the interpolation. Furthermore, the statistical homogenisation of the data allows avoiding the biggest errors of initial observations.

The spatial structure of the wind speed is derived without the finest spatial structure of the region. Of course, at higher altitudes where the wind turbines are generally operated, the wind field is smoother. Nevertheless, the real wind turbines would need site-specific dynamical modelling as generally requested in the feasibility studies.

The observed trends are convincing both for the increasing global radiation and for the decreasing wind speed. The positive experience of the validation for global radiation supports the established trends, which cannot be repeated for wind speed cubes. Moreover, the trends do not necessarily mean that they continue in the future if the global warming continues.

Acknowledgements: The study was supported by the TÁMOP-4.2.2.A-11/1/KONV-20120016 Project in Hungary. The gridded data are downloaded from Open Access data base derived by the CarpatClim Project (http://www.carpatclim-eu.org/pages/home/).

\section{REFERENCES}

Angström, A. 1924. Solar and terrestrial radiation. Quarterly Journal of the Royal Meteorological Society 50. 121-125.

IPCC 2013. Climate Change 2013. The Physical Science Basis. Final version. http://www.ipcc. ch/report/ar5/wg1/) $2260 \mathrm{p}$.

PrescotT, J.A. 1940. Evaporation from a water surface in relation to solar radiation. Transactions of the Royal Society of South Australia 64. 114-118.

Szentimrey, T. 1999. Multiple Analysis of Series for Homogenization (MASH). Proceedings of the Second Seminar for Homogenization of Surface Climatological Data. Budapest; WMO, WCDMP-No. 41. 27-46.

Szentimrey, T. and Bihari, Z. 2006. MISH (Meteorological Interpolation based on Surface Homogenized Data Basis). In The use of GIS in climatology and meteorology. Eds. Tveito, O.E. et al. COST Action 719. Final Report,. The use of GIS in climatology and meteorology. Eds. Tveito, O.E. et al. 54-56. 


\section{Changing Ethnic Patterns of the Carpatho-Pannonian Area from the Late $15^{\text {th }}$ until the Early $21^{\text {st }}$ Century}
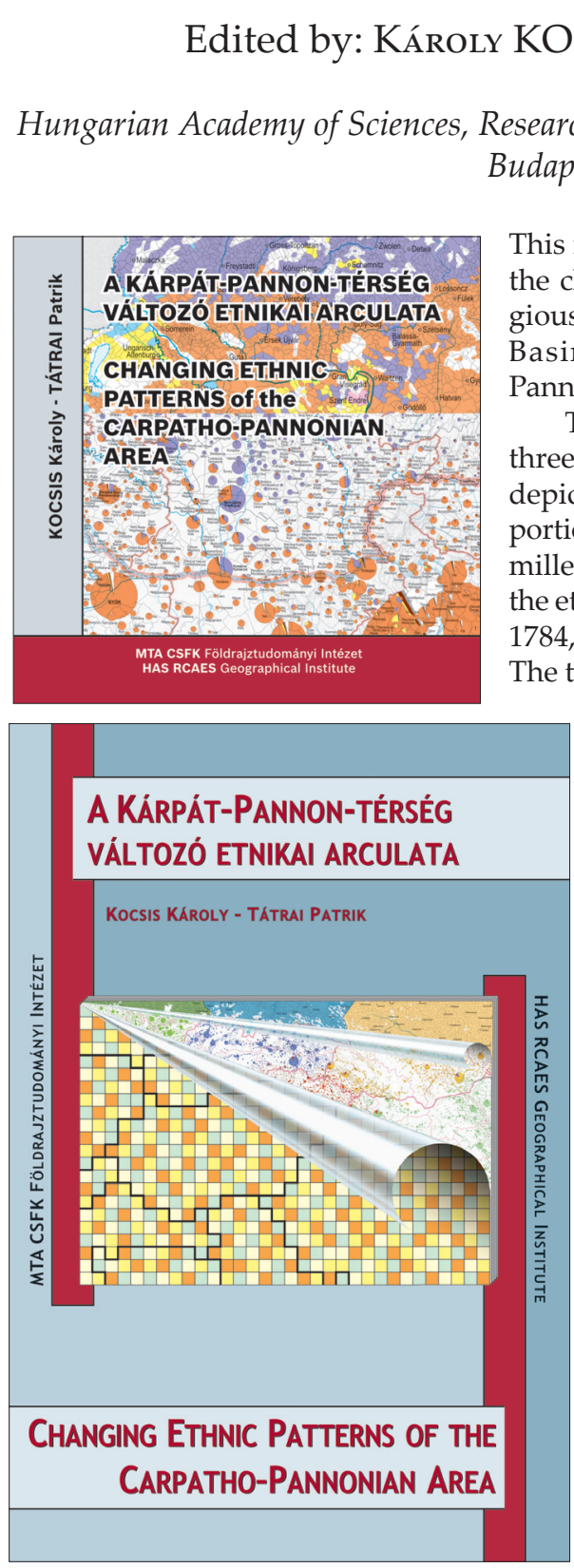

This is a collection of maps that visually introduces the changing ethnic patterns of the ethnically, religiously, culturally unique and diverse Carpathian Basin and its neighbourhood, the CarpathoPannonian area.

The Hungarian and English volume consist of three structural units. On the main map, pie charts depict the ethnic structure of the settlements in proportion to the population based on census data et the millennium. In the supplementary maps, changes of the ethnic structure can be seen at nine dates (in 1495, 1784, 1880, 1910, 1930, 1941, 1960, 1990 and 2001). The third unit of the work is the accompanying text, which outlines the ethnic trends of the past five hundred years in the studied area.

The antecedent of this publication is the "series of ethnic maps" published by the Geographical Research Institute of the Hungarian Academy of Sciences from the middle of the 1990's, which displayed each of the regions of the Carpathian Basin (in order of publication: Transylvania, Slovakia, Transcarpathia, Pannonian Croatia, Vojvodina, Transmura Region, Burgenland, Hungary). This work represents, on the one hand, the updated and revised version of these areas, and, on the other hand, regions beyond the Carpathian Basin not included on previous maps. Thus, the reader can browse ethnic data of some thirty thousand settlements in different maps.

Price: EUR 12.00

Order: Geographical Institute RCAES HAS Library

H-1112 Budapest, Budaörsi út 45.

E-mail: magyar.arpad@csfk.mta.hu 